\title{
An Asymmetric Synthesis of PPAR- $\gamma$ Agonist Navaglitazar from (+)-Methyl (2S,3R)-3-(4-methoxyphenyl)glycidate
}

\author{
John R. Rizzo and Tony Y. Zhang*
}

\begin{abstract}
An asymmetric synthesis of navaglitazar, a peroxisome proliferator activated receptor (PPAR) $\gamma$ agonist from commercially available (+)-methyl (2S,3R)-3-(4-methoxyphenyl)glycidate, is described. The new synthesis features high overall yield, low solvent usage, crystalline intermediates and operational simplicity.
\end{abstract}

Keywords: Asymmetric synthesis · Navaglitazar · Noninsulin dependent diabetes mellitus (NIDDM) ·

Peroxisome Proliferator Activated Receptor (PPAR) $\gamma$ agonist

\section{Introduction}

Navaglitazar (LY 519818) is a potent peroxisome proliferator activated receptor (PPAR)- $\gamma$ agonist currently undergoing Phase II clinical studies for noninsulin dependent diabetes mellitus (NIDDM)[1]. PPAR is a super family of nuclear transcription factors that include steroid, retinoid, and thyroid hormone receptors. A $\gamma$-selective agonist is highly sought after as potential agent to lower plasma glucose levels without increasing plasma insulin levels or causing hypoglycemia. Unlike the traditional agents of the thiazolidinedione (glitazones) family for the treatment of NIDDM, this compound belongs to the dihydrocinnamic acid family composed only of carbon, hydrogen and oxygen atoms.

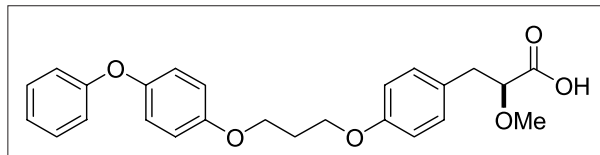

1. Navaglitazar, LY 519818

Initially, the desired $S$-enantiomer of the compound was obtained via chiral preparative chromatography separation of the ra-

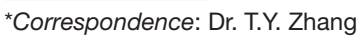

Eli Lilly and Company

Chemical Product Research and Development Division Lilly Corporate Center Indianapolis, IN 46285

USA cemic 1 , which was in turn prepared by the coupling of alkyl bromide 2 with phenol 3 in the racemic form (Scheme 1).

As the program moved along a need emerged for more material to enable toxicological studies with longer duration and across several species, and an alternative to chiral chromatography to access $\mathbf{1}$ was developed (Scheme 2). Specifically, aldol condensation of aldehyde 4 and methyl methoxyacetate (5) afforded an unstable benzylic alcohol, which had to be trapped in situ with trifluoroacetic anhydride to prevent reverse aldol. Hydrogenolysis via heterogeneous palladium catalysis successfully removed the benzyl protecting group as well as the secondary trifluoroacetoxyl group to afford methyl ester $\mathbf{6}$. Attempts to resolve racemic 7 obtained from saponifica- tion of (+/-)-6 with a wide variety of chiral bases met with disappointment; however, an enzymatic hydrolysis with the cross-linked enzyme crystal (Chiral CLEC-CR) coupled with the diastereomeric salt formed from (-)-cinchonidine afforded acid 7 in $>98 \%$ ee. Compound $\mathbf{3}$ obtained in this fashion was used to prepare a large amount of $\mathbf{1}$ in multi-kg quantities with high enantiomeric purity following similar coupling condition as for the racemate.

Although this enzymatic resolutionbased approach to 1 enabled fast delivery of high quality material for early phase clinical development, the throughput of the overall sequence left much for improvement. The operations associated with the establishment of the lone stereocenter within the molecule were quite complex.

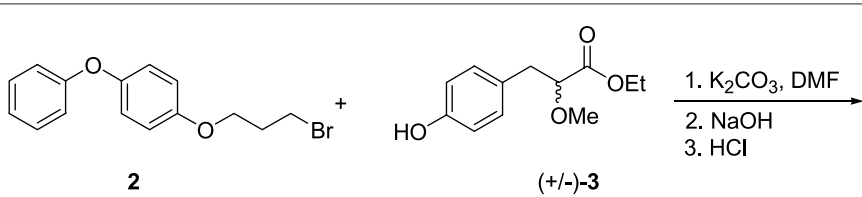

$(+/-)-3$

Scheme 1.

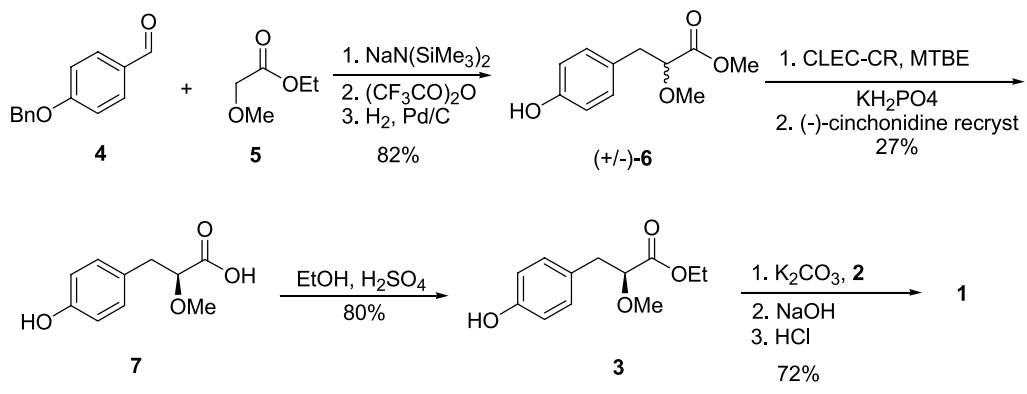

Scheme 2. 
Towards addressing these concerns, we were particularly intrigued by the possibility of utilizing glycidate $\mathbf{8}(2 S, 3 R)$ as a chiral building block for 1 (Scheme 3 ).

Glycidate 8, specifically the $(2 R, 3 S)$-enantiomer, has attracted significant attention as it constitutes a key starting material for the synthesis of $(2 S, 3 S)$-diltiazem (11) [2], an antihypertensive, anti-anginal vasodilator marketed by Tanabe and several companies across the globe. For obvious commercial reason the supply of $(2 R, 3 S)-\mathbf{8}$ is of considerable commercial and academic interest. Disclosed synthetic routes for $(2 R, 3 S)-8$ include asymmetric epoxidation of $p$-MeO-cinnamate [3], enantioselective reduction of 2-chloroketoesters [4], kinetic resolution via enzymatic hydrolysis [5] or transesterificaion [6], and resolution of bromo- and iodohydrins [7].

Of particular commercial viability is the Darzens condensation reaction coupled with enzymatic hydrolysis to afford $(2 R, 3 S)-\mathbf{8}$, and $(2 R, 3 S)-12$ (Scheme 4). Because only the compound of $2 R, 3 S$ configuration is of interest for diltiazem production, we reckon that the unwanted enantiomers, namely esters like $(2 S, 3 R)-\mathbf{8}$, can be made useful by serving as a source of chiral building block for navaglitazar (1). In this report, we will describe an efficient and novel asymmetric synthesis of 1 from (+)-methyl (2S,3R)-3(4-methoxyphenyl)glycidate 8 .

\section{Results and Discussion}

Our initial efforts focused on finding an efficient way of converting $(2 R, 3 S)-8$ into compound 3 in order to take advantage of intersecting with the existing route. Establishing this approach would entail

i) the reduction of the benzylic $\mathrm{C}-\mathrm{O}$ bond,

ii) demethylation of the phenyl ether and

iii) methylation of the chiral alcohol to afford methyl ether.

The reduction of the benzylic epoxide went uneventfully. Thus $(2 R, 3 S)-8$ was hydrogenated using $5 \%$ palladium on carbon

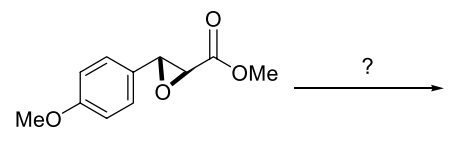

$2 S, 3 R-8$

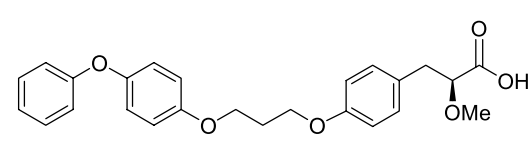

1

Scheme 3.

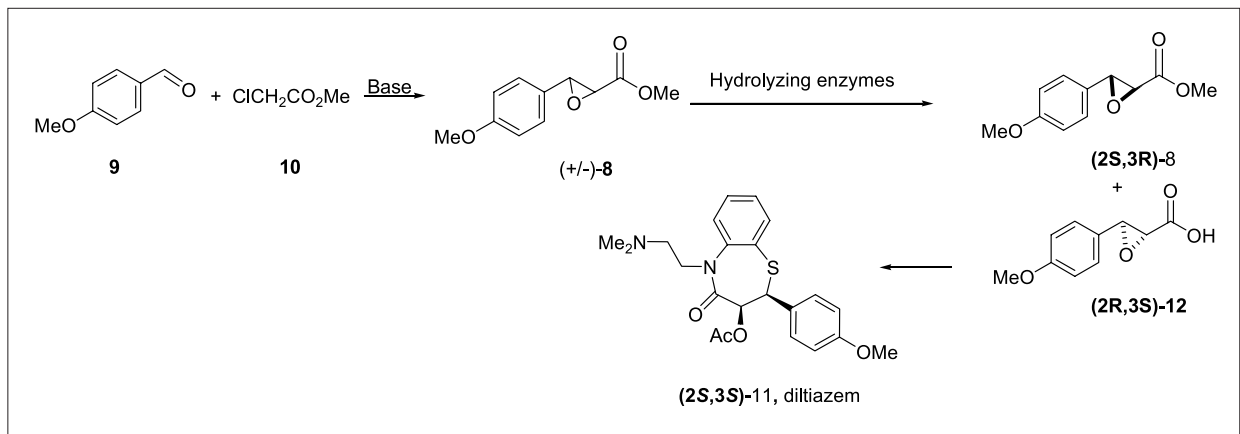

Scheme 4.

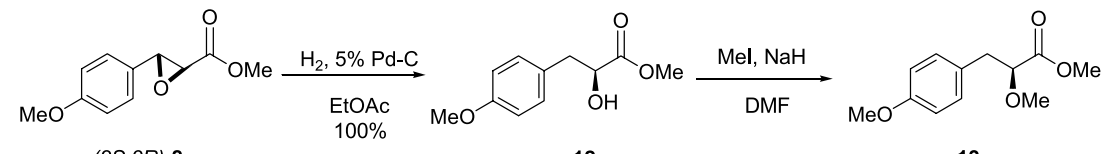

$(2 S, 3 R)-8$

12

13

$\mathrm{BCl}_{3}$ or $\mathrm{BBr}_{3}$

Scheme 5.

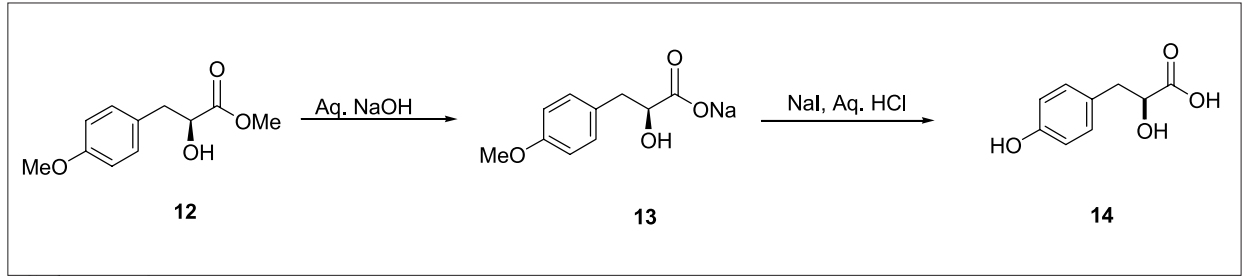

Scheme 6.

in ethyl acetate at ambient temperature to provide methyl $p$-MeO-2-hydroxydinhydrocinnamate (13) as a low melting solid in quantitative yields (Scheme 5).

Compound $\mathbf{1 2}$ could be methylated at this point using methyl iodide and sodium hydride in DMF to provide the methyl ether 13 with three chemodifferentiated methoxy groups. Attempts to selectively demethylate at the phenol site were not successful. Boron reagents such as $\mathrm{BBr}_{3}$ and $\mathrm{BCl}_{3}$ were actually selective at demethylating the alkyl methyl ether over the phenol methyl ether and the ester methyl. This reactivity is plausible because boron could associate with oxygens from both the carbonyl and the methyl ether to form a five-membered ring complex, activating the methyl ether selectively. Sulfur-based nucleophilic reagents such as sodium ethanethiolate cleaved both ethers non-selectively. Other nucleophiles such as lithium iodide gave no reaction. Strong acids such as hydrogen bromide and hydrogen iodide also demethylated both sites. In summary, a selective demethylation reaction in preference for the phenyl ether was not within reach.

On the other hand the fully deprotected trihydroxy compound $\mathbf{1 4}$ could be obtained readily. Toward this end, crude alcohol $\mathbf{1 2}$ from hydrogenation was hydrolyzed using sodium hydroxide and ethanol to provide the sodium salt $\mathbf{1 3}$ in quantitative yields. Demethylation was accomplished using an aqueous solution of $\mathrm{HI}$ at reflux. Although hydriodic acid is expensive and unstable as a commercial reagent, we discovered that an effective source of hydroiodic acid could be generated conveniently in situ using sodium iodide and aqueous $\mathrm{HCl}$ (Scheme 6). The reaction is simply conducted in water at reflux. Upon completion of the reaction, the solution was cooled to ambient temperature and compound $\mathbf{1 4}$, a well-behaved crystalline compound, precipitated directly from the reaction as the free acid. The reaction yields range from $47-79 \%$. The variability of yields was largely due to the water solubility of $\mathbf{1 4}$. The crude product can be further purified by a reslurry in MTBE or dissolving in acetonitrile and filtering off any insoluble inorganic salts.

When the protected ester $\mathbf{3}$ serves as the head piece, alkyl bromide $\mathbf{2}$ has to be used under carefully controlled conditions to avoid epimerization of the $\alpha$-stereocenter under basic conditions. Although compound $\mathbf{1 4}$ also bears an $\alpha$-stereocenter, we recognize that presence of the two adjacent ionizable hydroxyl protons would protect the $\alpha$-carbon from epimerization via deprotonation, and hence much harsher coupling conditions could be employed to take advantage of the less reactive and less expensive chloride tailpiece. 
The fully deprotected headpiece $\mathbf{1 4}$ was then coupled efficiently with the tailpiece 15 using aqueous sodium hydroxide and DMSO at reflux (Scheme 7). The reaction is then cooled to ambient temperature, MTBE is added and the product precipitates directly from the reaction mixture as the sodium salt. After drying, $\mathbf{1 6}$ is conveniently dimethylated using sodium hydride and methyl iodide in DMF to give 17. The methyl ester can then be hydrolyzed using aqueous sodium hydroxide in ethanol to provide the $\mathbf{1}$ as the sodium salt. The sodium salt of the active pharmaceutical ingredient can be further purified by a recrystallization from ethyl acetate if needed. The enantiomeric excess of $\mathbf{1}$ was $99.7 \%$ (as determined by chiral HPLC) starting from $(2 R, 3 S)-8$, which compares favorably with that obtained typically from the enzymatic hydrolysis process (96-98\%).

\section{Conclusions}

We have developed a seven-step asymmetric synthesis of navaglitazar from the commercially available (+)-methyl $(2 S, 3 R)$ 3-(4-methoxyphenyl)glycidate, which is essentially a byproduct from diltiazem production and can be accessed at very low cost. The process is high yielding, requires low solvent volumes, features crystalline intermediates and requires no chromatographic separations (see Experimental Section). Conditions employed in the synthesis are typically acid-base chemistry which is simple to operate and robust to repeat. The protective effect of the free carboxylate in 14 allows the use of less reactive chloride tailpiece $\mathbf{1 5}$ in place of bromide 2, without the risk of epimerizing the $\alpha$-stereocenter. Compared with the existing route using enzyme to resolve (+/-)-6 and (-)-cinchonidine to upgrade, this new process is much higher in throughput and significantly more cost effective for accessing the enantiopure intemediate 14. This new approach provides a valuable option for preparing $\mathbf{1}$. We do, however, recognize that the current condi- tions $(\mathrm{NaH} / \mathrm{MeI} / \mathrm{DMF})$ to install the methyl ether are not acceptable for large scale production and we have been investigating alternative methods, with some very promising results. These and others will be reported in connection with the synthesis of compounds of similar structural motif in the near future.

\section{Experimental Section}

\section{2}

(+)-Methyl (2S,3R)-3-(4-methoxyphenyl)glycidate $(\mathbf{8}, 750 \mathrm{~g})$ was dissolved in 7.51 of ethyl acetate and shaken in a Parr reactor with $375 \mathrm{~g}$ of $5 \% \mathrm{Pd}-\mathrm{C}(\mathrm{w} / \mathrm{w})$ under 45 psid hydrogen at ambient temperature for $16 \mathrm{~h}$. The catalyst was filtered and the filtrate was concentrated under vacuum to give an oil, which was seeded and allowed to stand at ambient temperature to give 745 $\mathrm{g}$ of $\mathbf{1 3}$ as a solid.

\section{3}

Compound 12 (745 g) was dissolved in 3.7251 of ethyl acetate at ambient temperature. Sodium hydroxide $(3.548 \mathrm{l}, 5 \mathrm{~N})$ was added dropwise and stirred for $3 \mathrm{~h}$ after the addition. The ethanol solvent was exchanged with 41 of isopropyl acetate. The slurry was cooled to $0{ }^{\circ} \mathrm{C}$ and filtered. The filter cake was washed with 21 of $\mathrm{iPrOH}$ and $4 \mathrm{l}$ of MTBE. The white solid was collected and dried in a vacuum oven at $60{ }^{\circ} \mathrm{C}$ to provide $888.6 \mathrm{~g}$ of $\mathbf{1 3}$.

\section{4}

Compound 13 (218 g, $1 \mathrm{~mol})$ and sodium iodide (375 g, $2.5 \mathrm{~mol}$ ) were dissolved in 11 of concentrated hydrochloric acid at ambient temperature. The solution was heated to reflux for $6 \mathrm{~h}$ and then cooled in an ice-water bath for $2 \mathrm{~h}$. The slurry was filtered and the filter cake was washed with $300 \mathrm{ml}$ of cold water. The white solid was collected and dried in a vacuum oven at $60{ }^{\circ} \mathrm{C}$ to provide $178.7 \mathrm{~g}$ of crude solid, which was stirred in 21 of acetonitrile for 1 $\mathrm{h}$ at ambient temperature. The solution was filtered and the filtrate was concentrated

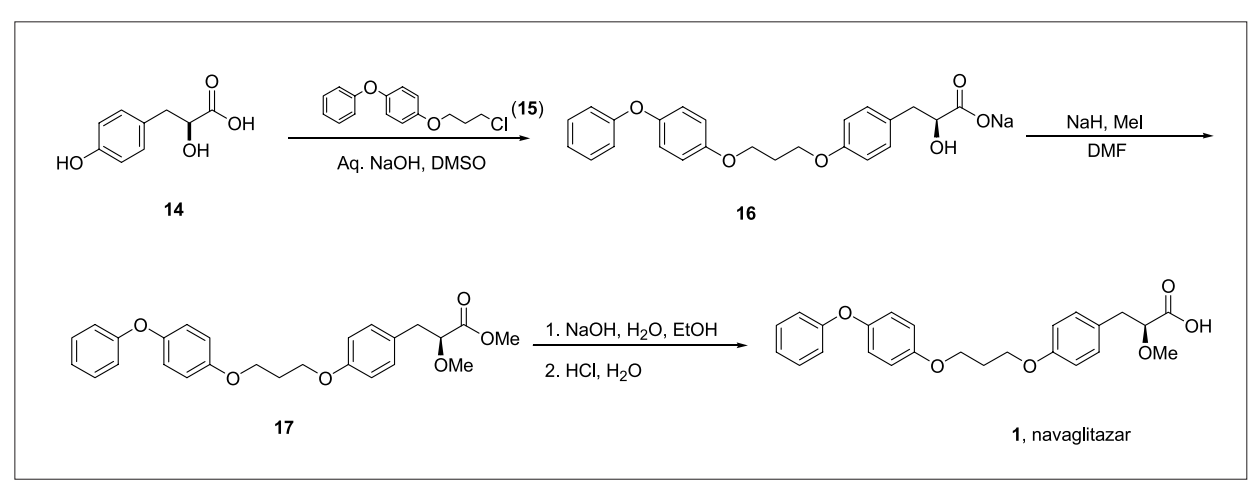

Scheme 7.

under vacuum to provide $123 \mathrm{~g}$ of $\mathbf{1}$ as an off-white solid.

\section{6}

To a $250 \mathrm{ml}$ three-neck round bottom flask was added 14 (10.63 g, $58.35 \mathrm{mmol})$ followed by $5 \mathrm{~N} \mathrm{NaOH}(29.2 \mathrm{ml}, 145.88$ mmol). The mixture was stirred at ambient temperature for $35 \mathrm{~min}$. To the solution was added 15 (18.39 g, $69.99 \mathrm{mmol})$ in $30 \mathrm{ml}$ of DMSO. The resulting solution was heated to reflux for $3 \mathrm{~h}$. While cooling, $106.3 \mathrm{ml}$ of water was added and stirred for an additional hour. The solid was filtered and washed with $106.3 \mathrm{ml}$ of MTBE. The solid was collected and dried under vacuum at $60^{\circ} \mathrm{C}$ for $16 \mathrm{~h}$ to provide $19.49 \mathrm{~g}$ of $\mathbf{1 6}$.

\section{7}

To a $250 \mathrm{ml}$ flask added was added 16 (15.11 g, $35.10 \mathrm{mmol})$, followed by $76 \mathrm{ml}$ of dry DMF. The resulting mixture was stirred for $5 \mathrm{~min}$ at room temperature then cooled in ice-water bath. NaH (1.78 g, $44.50 \mathrm{mmol}$; $60 \%$ in mineral oil) was added and stirred for $5 \mathrm{~min}$ while monitoring $\mathrm{H}_{2}$ evolution. The bath was removed and stirred for $15 \mathrm{~min}$, and ice-bath was replaced. Iodomethane $(6.56 \mathrm{ml}, 105.31$ mmol) was added dropwise via an addition funnel. After being stirred in bath for $1 \mathrm{~h}$, then $3 \mathrm{~h}$ at room temperature, the mixture was quenched with $250 \mathrm{ml}$ of water and extracted with $250 \mathrm{ml}$ of EtOAc. The EtOAc layer was washed with $3 \times 250 \mathrm{ml}$ water, followed by washing with $250 \mathrm{ml}$ of brine. The organic phase was dried over $\mathrm{MgSO}_{4}$, filtered, and concentrated under vacuum to afford $13.85 \mathrm{~g} \mathbf{1 7}$ as a yellow oil.

\section{Navaglitazar Sodium}

Compound 17 (13.85 g, $31.77 \mathrm{mmol})$ and absolute EtOH $(138.5 \mathrm{ml})$ were added to a 11 flask. The solution was stirred with cooling (ice water bath). A solution of $5 \mathrm{~N}$ $\mathrm{NaOH}(63.5 \mathrm{ml}, 317.66 \mathrm{mmol})$ was added via addition funnel over $13 \mathrm{~min}$. Stirring was continued for $1 \mathrm{~h}$ at room temperature. The flask was cooled in ice-water bath with stirring for an additional hour. The precipitate was filtered, washed with $250 \mathrm{ml}$ of cold absolute EtOH, and then 11 of MTBE. The solid was collected and dried in a vacuum oven set at $60{ }^{\circ} \mathrm{C}$ overnight to afford $7.92 \mathrm{~g}$ of navaglitazar sodium as a white powder. A portion $(7.86 \mathrm{~g}, 17.68 \mathrm{mmol})$ was dissolved in EtOAc ( $86.5 \mathrm{ml}, 11 \mathrm{vol})$ and heated to reflux under nitrogen. After $2.5 \mathrm{~h}$, the heat source was removed and the solution was allowed to cool slowly to room temperature. Once at room temperature the solution was stirred for $1 \mathrm{~h}$. The precipitate was filtered, washed with $300 \mathrm{ml}$ of MTBE, and dried in vacuo at $60^{\circ} \mathrm{C}$ for $16 \mathrm{~h}$, affording $7.21 \mathrm{~g}$ navaglitazar sodium. 


\section{Navaglitazar (1)}

The Na salt of 1 (2.50 g, $5.62 \mathrm{mmol})$ was dissolved in $25 \mathrm{ml}$ of deionized water and was heated to $60{ }^{\circ} \mathrm{C}$. $1 \mathrm{~N} \mathrm{HCl}(6.2 \mathrm{ml}$, $6.19 \mathrm{mmol}$ ) was added and the resulting mixture was stirred for $15 \mathrm{~min}$, heated to $70{ }^{\circ} \mathrm{C}$, and allowed to cool to ambient temperature without agitation. The agitation was resumed at ambient temperature for 45 min. The solid was filtered, washed with 20 $\mathrm{ml}$ of deionized water. Drying in vacuum oven at $60{ }^{\circ} \mathrm{C}$ for $16 \mathrm{~h}$ gave $2.23 \mathrm{~g}$ of 1 as a white solid.

\section{Acknowledgement}

The authors wish to thank Mr. Jacob R. Ramecle for technical assistance, and Tanabe Inc. for a sample of $\mathbf{8}$.

Received: June 6, 2006

[1] J.A. Martin, D.A. Brooks, L. Prieto, R. Gonzalez, A. Torrado, I. Rojo, B. Lopez de Uralde, C. Lamas, R. Ferritto, M. Dolores Martin-Ortega, J. Agejas, F. Parra, J.R. Rizzo, G.A. Rhodes, R.L. Robey, C.A. Alt, S.R. Wendel, T.Y. Zhang, A. Reifel-Miller, C. Montrose-Rafizadeh, J.T. Brozinick, E. Hawkins, E.A. Misener, D.A. Briere, R. Ardecky, J.D. Fraser, A.M. Warshawsky, Bioorg. \& Med. Chem. Lett. 2005, 15, 51-55.

[2] J. Elks, C.R. Ganellin, 'Dictionary of Drugs', Chapmann and Hall; London, 1990; p 426.

[3] a) A. Solladie-Cavallo, L. Bouerat, Org. Lett. 2000, 2, 3531-3534; b) A. Solladie-Cavallo, L. Bouerat, L. Jierry, Eur. J. Org. Chem. 2001, 4557-4560; c) A. Solladie-Cavallo, L. Jierry, A. Klein, Comptes Rendus Chimie 2003, 6, 603-606; d) A. Solladie-Cavallo, L. Jierry, A. Klein, M. Schmitt, R. Welter, Tetrahedron: Asymm. 2004, 15, 3891-3898.

[4] T. Shibatani, T. Nishida, H. Matsumae, Tanabe Seiyaku Co., Ltd., Japan, EP 447938, 1991.

[5] a) T. Shibatani, R. Yoshioka, H. Matsumae, A. Idei, WO 9922014, 1999; b) M. Furui, H. Higaki, K. Nakamichi, H. Seko, JP 09037791, 1997.

[6] A. Gentile, C. Giordano, C. Fuganti, L. Ghirotto, S. Servi, J. Org. Chem. 1992, 57, 6635-7.

[7] N. Anand, M. Kapoor, S. Koul, S.C. Taneja, R.L. Sharma, G.N. Qazi, Tetrahedron: Asymm. 2004, 15, 3131-3138. 